extreme red in another, if the colour character of the detail being searched for is unknown.

By modifying such extreme measures as just described, it is obviously possible by photography to intensify or diminish the apparent effect of any colour, and so, as for example in stained physiological sections, to improve on the original, or from one original to get two (or more) photographs that represent the section in, as it were, two (or more) different conditions as to staining.

The photographer has also by such means a very large measure of control over the effect of mist. The writer has shown that light is scattered by particles of a diameter equal to half a wavelength of the scattered light. By passing a brilliant pencil of light through a flask of filtered distilled water the path of the pencil may be scarcely visible (the "Tyndall effect"). But by photographing the arrangement on an ordinary plate, that is, using blue and ultra-violet light, the path of the light will probably be shown very conspicuously indeed, the particles that escaped removal by filtration being not large enough to scatter light of greater wave-length than the ultra-violet and the extreme blue. When the particles of the mist or turbidity are graduated in size, as they generally are, and are not coarse like the dust that may be stirred up from a dry road, then the longer the wave-length of the light used the less does the mistiness show in the photograph. When the air is misty, by the use of a yellow filter distant objects may be photographed more clearly than they can be seen, and by using only infra-red light Prof. Wood has obtained photographs in which the sun shines, though there was only a grey cloudiness visible.

Though the colour sensitising of plates is now as much the manufacturer's business as the preparation of emulsions and the coating of the plates therewith, the experimentalist may wish to try the effect of a dye for himself. The solution must be very weak indeed, say one of the dye to from ro, ooo to 50,000 times its weight of water. Ammonia is often advantageous to the extent of one per cent. of the whole. The best formula is simply a nuatter of experiment. The following, for example, is a varation recently published by Messrs. Michaud and Tristan (Brit. Jnl. of Phot., lxii., 56) for sensitising for the red and infrared :-

Alcohol 5o per cent., 200 c.c.

Ammonia, 4 c.c.

Alizarin blue S, 0.04 gram.

Silver nitrate ro per cent. solution, 5 drops.

The same dye is efficient without the silver salt and the alcohol, but presumably these are advantageous. In general, after the plate has been in the dye solution for two or three minutes, it is washed for a few minutes and then dried. Plates so treated vary very much as to the time that they will remain in good condition. For example, plates bathed in the solution quoted above must be used within a few hours, but in other cases they may last for months.

$$
\text { NO. } 2365 \text {, VOL. 94] }
$$

It is much less risky to make colour filters than to bathe plates, as most dye solutions will be absorbed by a clean gelatine film. But colour filters are now made by several firms, and the Wratten department of Kodak catalogues standardised colour filters of nearly a hundred different transmissions.

Chapman Jones.

\section{PROF. G. F. J. ARTHUR AUWERS}

$\mathrm{TE}$ brief paragraph in our issue of last week, announcing the death of Prof. Auwers, must have been read with the deep regret that follows the loss of one who long occupied a commanding position in the world of science, and whose place it will be difficult to fill. For more than fifty years he had illuminated the science of astronomy, and by providing much of the material by which it is hoped to attack successfully the problem of the structure of the sidereal universe, he linked together the astronomical thoughts and methods of the past with the philosophical problems that engross and captivate the attention of astronomers of to-day.

In the history of astronomy of position, by which is understood the accumulation and arrangement of facts depending on a star's place in the sky, three names stand out prominently. Bradley, in whose valuable series of observations, long waiting for an interpreter, lay hidden the secret of stellar proper motion; Bessel, who made these measures available to the astronomers of his day; and Auwers, whose early appreciation of the necessity of the highest accuracy gave to these observations an increased value by his long and patient examination, laying. the foundation of that system of thorough uniformity which has welded meridian observations into a more consistent whole, facilitating the combination of star catalogued places on a common basis, by the removal of systematic errors or discrepancies. Auwers taught the necessity for a higher standard of accuracy, and it is not too much to say that in the department of reduction and discussion of observations he long stood without a rival. His forte lay in the control and management of large masses of work, in the unhurried, careful supervision of every stage, bringing an acute and trained judgment to bear eyually on all parts of the investigation.

If his reputation rests especially on his re-reduction of Bradley, it must be remembered that he encouraged and assisted other large undertakings. He tr - a prominent part in the re-observation of the Durchmusterung zones, a work of many years' international co-operation successfully carried out under the auspices of the Astronomische Gesellschaft. He was among the first to investigate the proper motion of faint stars, and he foreshadowed some of the conclusions that have been established by the most modern and thorough of inquiries. The determination of solar parallax by the method of the transit of Venus is a somewhat discredited problem now, but forty 
years ago it occupied a very conspicuous position, and Auwers's work on the German share in the complete investigation exhibits at least all that could be derived from the process. Of still earlier date, and of unquestioned excellence and success, were his discussions of the variable proper motion of Sirius and Procyon. How brilliantly his location of the position of the unsuspected satellites was justified, is well known.

It would be impossible to do justice in a short notice to talents so varied and to an industry so active as Auwers exhibited throughout a long career, but it may be permitted to say that, notwithstanding the bitter estrangement that separates us from German thought and German ambitions, every English astronomer would be willing to lay a tribute of respect on the grave of Arthur Auwers.

W. E. P.

\section{NOTES.}

Sir Anthony A. Bowlby has been chosen Bradshaw lecturer of the Royal College of Surgeons of England for the ensuing year.

IT is announced in Science that Prof. R. $H$. Richards, professor emeritus in the Massachusetts Institute of Technology, has been awarded the gold medal of the Mining and Metallurgical Society of America in recognition of his services in the advancement of the art of ore dressing.

Ar the meeting of the Royal Geographical Society on Monday, February 22, Dr. Page, the American Ambassador, presented to Dr. Scott Keltie, secretary of the Royal Geographical Society, the Cullum gold medal for long and eminent service to geography, awarded by the American Geographical Society.

THE gold medal of the Institution of Mining and Metallurgy - the "blue ribbon" of the profession-has been awarded to a distinguished Canadian, Dr. Willet G. Miller, provincial geologist of Ontario, in recognition of the eminent services rendered to mining by his admirable work as an economic geologist.

THE officers of the Royal Astronomical Society elected at the annual meeting on February 12 were as follows :-President, Prof. R. A. Sampson; VicePresidents, Dr. J. W. L. Glaișher, Major E. H. Hills, Dr. W. H. Maw, and Prof. H. H. Turner; Treasurer, Mr. E. B. Knobel; Secretaries, Prof. A. S. Eddington and Prof. A. Fowler; Foreign Secretary, Prof. Arthur Schuster.

Prince B. Galitzin has been elected an honorary fellow of the Physical Society. The following is the list of officers of the society elected for the ensuing year :-President, Sir J. J. Thomson. Secretaries, Dr. S. W. J. Smith (Royal College of Science, S.W.), and Dr. W. Eccles (University College, Gower Street, W.C.). Foreign Secretary, Dr. R. "T. Glazebrook. Treasurer, W. Duddell. Librarian, Dr. S. W. J. Smith.

AT the annual general meeting of the Geological Society, held on February 19, the following officers were clected:--President, Dr. A. Smith Woodward; NO. 2365 , VOL. 94]
Vice-Presidents, Dr. H H. Bemrose, Mr. Clement Reid, Dr. A. Strahan, and the Rev. H. H. Winwood"; Secretaries, Dr. H. H. Thomas and Dr. H. Lapworth; Foreign Secretary, Sir Archibald Geikie, O.M., K.C.B.;Treasurer, Mr. B. McNeill. The president's address delivered at the meeting dealt with the evolution of the fishes in geological time.

The virtual German monopoly in the manufacture of dye-wares is a matter of national concern in other countries as well as in Britain. It is announced that arrangements have been made by the Benzol Products Company of Philadelphia to commence dye manufacturing on a large scale in about six months' time. A new company, styled the "Russian Society of Chemical Industry," has also been formed in Moscow to manufacture dyes for the sixty large consumers in that district.

ON Tuesday next, March 2, Prof. W. J. Pope will begin a course of two lectures at the Royal Institution on colour photography (scientific applications): (1) "Photographic Appreciation of Colour in Monochrome "; (2) "Photography in Natural Colours"; and on Thursday, March 4, Sir Herbert Warren will begin a course of two lectures on poetry and war. The Friday evening discourse on March 5 will be delivered by Prof. E. B. Poulton on mimicry and butterflies, and on March 12 by Sir Rickman J. Godlee on back to Lister.

News has been received of the arrival at Khartum of Dr. C. Christy, who has been engaged during the past three years on a zoological mission in the Belgian Congo undertaken officially on behalf of the museum at Tervueren. We hear that he has made very large collections of the animals of the Ituri forest and other regions of the Congo traversed by him, though it is difficult to say what is to become of the specimens under the conditions existing in Brussels. Dr. Christy was fortunate in shooting two okapi, thus joining the very small band (not more than three or four) of white men who have shot an okapi. Nearly all the specimens now in Europe were killed by natives. Dr. Christy's bag also included several specimens of Meinertzhagen's great black forest pig and many of the dwarf Ituri buffalo.

Science announces the following deaths of men known in the scientific world:-Dr. Anthony Woodward, at one time assistant in the department of geology and for thirty-seven years librarian of the American Museum of Natural History, New York City; M. Alfred Tournier, formerly professor of viticulture at the University of California and later connected with the U.S. Department of Agriculture, who was killed on December $\mathrm{I2}$ in the war; Dr. C. F. Brackett, professor emeritus of physics in Princeton University, in his eighty-second year; Dr. B. Sharp, formerly corresponding secretary of the Philadelphia Academy of Natural Sciences and professor of invertebrate zoology there and in the University of Pennsylvania, aged fifty-six years.

WE regret to announce that among the victims of the war must be numbered M. Joseph Déchelette, 